\title{
Poder germinativo de sementes de doze espécies florestais da região de Manaus. I
}

\author{
Jurandyr da Cruz Alencar (") \\ Luis Mauro S. Magalhães (")
}

\begin{abstract}
Resumo
A germinação de sementes de doze espécies florestais da região de Manaus foi investigada visando-se a obter informações para cultura destas espécies. Curvas de percentagem de germinação em função do tempo foram feitas, mostrando as distinções entre espécies quanto ao valor cultural destas sementes, assim como o período e a percentagem de germinação. Testes adicionais foram realizados (pureza, corte, flutuação e peso) dando uma caracterização melhor aos lotes estudados. Os autores apontam um bom potencial germinativo para estas espécies, sendo que nove delas apresentaram uma percentagem de germinação acima de $50 \%$ sem qualquer tipo de tratamento, num período máximo de 90 dias após a semeadura.
\end{abstract}

\section{INTRODUÇÃo}

A intensificação da exploração florestal na Amazônia sem o devido conhecimento das espécies que ocorrem na região pode conduzir a perdas de recursos bastante valiosos. Pandolfo (1978) em estudo com enfoque econômico - ecológico preconiza, entre outras medi. das, a recomposição efetiva das matas explo. radas como forma de se garantir a continuidade deste potencial econômico. A autora segue afirmando que o simples replantio de espécies exóticas de crescimento rápido não constitui garantia de suprimento para as indústrias consumidoras de madeira da região. Torna-se urgente, portanto, um maior conhecimento das espécies nativas quanto à sua silvicultura, de modo a permitir o replantio e a recomposição destas florestas de forma econômica.

Algumas espécies de alto valor econômico, como o Mogno (Swietenia macrophylla), têm sido investigadas (Araujo, 1971) com resultados de boa germinação para vários trata- mentos. O gênero Aniba também tem sido traIhado (Araujo, 1967 e 1970) com os resultados apresentando vários fatores importantes na germinação de Casca Preciosa (Aniba canelilla) e Pau-rosa (Aniba duckei). Pereira \& Pedroso (1973), estudando a influência da profundidade de semeadura em 4 essências, verificaram que esta apenas ocorreu em Favaorelha-de-negro (Enterolobium timbauva) e Pau-rosa-novo (Systemanophne mezii). Na re-gião de Belterra foi desenvolvido um trabalho com dezessete espécics (PRODEPEF, 1976), quanto à sua capacidade de germinação, sendo que onze destas espécies tiveram boa percentagem de sementes germinadas $(>50 \%)$ sem nenhum tipo de tratamento. Glesinger (1960) apresentou uma revisão de trabalhos desenvolvidos nos países da América Latina onde encontramos referências a várias espécies amazônicas, e onde pudemos notar as diferenças existentes no poder e período de germinação, entre espécies. Cumaru (Dipterix odorata) e Jutaí (Hymenaea courbaril) sãc duas espécies citadas, que apresentaram 80 e de 30 a $100 \%$ respectivamente de percentagem de germinação.

Os objetivos do presente trabalho são: $\left.1^{\circ}\right)$ - estudar a germinação de sementes de espécies nativas da região de Manaus, em condições uniformes e sem qualquer tipo de tratamento para acelerá-la; $2^{9}$ ) - fornecer informações para projetos posteriores visando determinar os melhores métodos e tratamentos para uniformização da germinação em espécies de interesse econômico e que tenham esta necessidade; $3^{\circ}$ ) - indicar métodos ade-quados para produção de mudas em espécies de interesse econômico.

(*) - Instituto Nacional de Pesquisas da Amazônia, Manaus. 
MATERIAL E MÉTODOS

A relação das doze espécies trabalhadas, bem como as datas da coleta e semeadura estão no quadro 1. Todas foram coletadas na Reserva Ducke, no $\mathrm{Km} 26$ da rodovia ManausItacoatiara, entre janeiro de 1977 e junho de 1978, de uma única matriz. Das doze espécies trabalhadas, apenas quatro (ver quadro 1) não têm uso atual no mercado, embora tenham bom bom potencial econômico futuro, por suas características físicas e mecânicas.

Após coletadas, as sementes eram postas para secagem, quando nececssário, à temperatura ambiente. Depois de retiradas dos frutos e secas, foram feitos testes adicionais para melhor caracterização dos lotes (pureza, flutuação, corte e peso), segundo Deichmann (1967). Os testes de germinação foram feitos em caixas germinadoras de $60 \mathrm{~cm} \times 20 \mathrm{~cm}$, cheias com areia lavada. Estas caixas foram colocadas em um galpão de germinação com cobertura de telhas de plástico transparente. Não foi efetuado qualquer tratamento para aumentar a germinação destas sementes. Para cada espécie, foram usadas quatro amostras com cinqüenta sementes por amostra. Após a semeadura, foram feitas observações diárias do número de sementes germinadas por amostra. Consideramos sementes germinadas aquelas que tiveram seu tegumento rompido, com posterior emissão do caulículo. Durante toda a experimentação foi mantida a umidade do substrato através de regas periódicas. Foram feitas observaçōes durante 90 dias para todas as espécies.

\section{Resultados}

Os resultados dos testes de germinação e adicionais são apresentados no Quadro 2. Foi registrado diariamente o número de sementes germinadas por amostra e por espécie. Quanto à percentagem de germinação, podemos distinguir dois grupos: o primeiro, seria de espécies com germinação acima de $50 \%$ (Cariniana micrantha, Couepia Iongipendula, Carapa guianensis, Scleronema micranthum, Eremoluma williamii, Parkia pendula, Dipteryx odorata, Anacardium spruceanum e Hymenaea courbaril), e o segundo, de espécies de baixo poder germinativo (Dinizia excelsa Stryphnodendron guianense e Caryocar villosum). Quanto ao valor cultural $(\%$ de germinação $x$ pureza), as espécies que se destacaram foram Couepia longipendula, Carapa guianensis e Dipteryx odorata, as três com valores acima de $75 \%$. Dinizia excelsa, Stryphnodendron guianense e Caryocar villosum tiveram valores baixos $(<50 \%)$, enquanto as outras espécies ocuparam uma faixa média. Nos testes de pureza ( $\%$ peso de sementes limpas e perfeitas na amostra), três

QUADRO 1 - Relação das sementes testadas

\begin{tabular}{|c|c|c|c|c|}
\hline \multirow{2}{*}{ NOME BOTÃNICO } & \multirow[b]{2}{*}{ NOME COMUM } & 1 & \multirow[b]{2}{*}{$\begin{array}{l}\text { DATA DE } \\
\text { COLETA }\end{array}$} & \multirow[b]{2}{*}{$\begin{array}{c}\text { DATA DE } \\
\text { SEMEADURA }\end{array}$} \\
\hline & & FAMILIA & & \\
\hline Dinizia excelsa Ducke & Angelim-pedra & Leguminosae & $13 / 09 / 77$ & $29 / 09 / 77$ \\
\hline Cariniana micrantha Ducke & Castanha-de-macaco & Lecythidaceae & $20 / 06 / 78$ & $21 / 06 / 78$ \\
\hline - Stryphnodendron guianense (Aubl.) & Falso-angelim & Leguminosae & $18 / 10 / 78$ & $20 / 10 / 78$ \\
\hline Couepia longipendula Pilger & Castanha-de-galinha & Lecythidaceae & $02 / 02 / 78$ & $04 / 02 / 78$ \\
\hline Carapa guianensis Aubl. & Andiroba & Meliaceae & $01 / 07 / 77$ & $02 / 07 / 77$ \\
\hline Scleronema micranthum Ducke & Cardeiro & Bombacaceae & $01 / 02 / 78$ & $02 / 02 / 78$ \\
\hline Eremoluma williamii Aubr. & Abiurana & Sapotaceae & $07 / 07 / 77$ & $08 / 07 / 77$ \\
\hline Caryocar villosum (Aubl.) Pers. & Piquiá-verdadeiro & Caryocaraceae & $15 / 07 / 77$ & $19 / 07 / 77$ \\
\hline - Parkia pendula Benth. & Visgueiro & Leguminosuae & $13 / 10 / 77$ & $17 / 10 / 77$ \\
\hline Dipteryx odorata (Aubl.) Willd. & Cumaru & Leguminoseae & $14 / 09 / 7 ?$ & $29 / 09 / 77$ \\
\hline Anacardium spruceanum Benth, ex Engl. & Cajui & Anacardiaceae & $17 / 10 / 77$ & $17 / 10 / 77$ \\
\hline Hymenaea courbaril & Jutai & Leguminoseae & $12 / 06 / 78$ & $15 / 06 / 78$ \\
\hline
\end{tabular}

\footnotetext{
(*) - Espécies sem utilizaçōo atual no mercado.
} 
QUADRO 2 - Testes adicionais e de germinação

\begin{tabular}{|c|c|c|c|c|c|c|c|c|}
\hline Espécie & $\begin{array}{c}\text { \% de ger- } \\
\text { minaçăo }\end{array}$ & $\begin{array}{l}\text { Período } \\
\text { (dias) }\end{array}$ & $\begin{array}{c}\text { Valor } \\
\text { cultural } \\
(\%)\end{array}$ & $\begin{array}{c}\text { Pureza } \\
(\% \\
\text { sementes } \\
\text { puras })\end{array}$ & $\begin{array}{c}\text { Corte } \\
(\% \text { sementes }(\% \\
\text { deficientes })\end{array}$ & $\begin{array}{c}\text { Flutuação } \\
\text { \% sementes } \\
\text { cheias) }\end{array}$ & $\begin{array}{l}\text { N.o sementes } \\
\text { por kg } \\
\text { puras }\end{array}$ & $\begin{array}{c}\text { Peso de } 1000 \\
\text { sementes } \\
\text { puras }(g)\end{array}$ \\
\hline Dinizia excelsa & 12,5 & 46 & 12,50 & 100,00 & 5,00 & 100,00 & 3.680 & 271,73 \\
\hline Cariniana micrantha & 73,5 & 23 & 69,17 & 94,12 & 0,00 & 100,00 & 1.125 & 888,00 \\
\hline Stryphnodendron guianense & 26,5 & 83 & 20,26 & 76,47 & 66,00 & 98,00 & 6.000 & 166,60 \\
\hline Couepia longipendula & 83,5 & 15 & 75,15 & 90,00 & 4,00 & 100,00 & 32 & 31.034 .40 \\
\hline Carapa guianensis & 78.0 & 61 & 76,14 & 97,62 & 17,00 & 100,00 & 52 & $19.158,00$ \\
\hline Scleronema micranthum & 88,00 & 67 & 58,08 & 66,00 & 0,00 & 100,00 & 7 & $132.000,00$ \\
\hline Eremoluma williamii & 67,5 & 41 & 67,50 & 100,00 & 1.00 & 100,00 & 150 & $6.666,60$ \\
\hline Caryocar villosum & 32,0 & 39 & 32,00 & 100,00 & 1,00 & 100,00 & 18 & $53.333,33$ \\
\hline Parkia pendula & 58,5 & 79 & 57,33 & 98,00 & nd & 100,00 & $10 \cdot 100$ & 99,00 \\
\hline Dipteryx odorata & 78,5 & 47 & 75,56 & 96,26 & 0,00 & 100,00 & 32 & $31,212,12$ \\
\hline Anacardium spruceanum & 57,5 & 17 & nd & nd & nd & nd & nd & nd \\
\hline Hymenaea courbaril & 67,0 & 24 & nd & nd & nd & nd & nu & nd \\
\hline
\end{tabular}

Legendo: $\mathrm{nd}=$ năo determinado.

essências apresentaram sementes compietamente puras $(100 \%)$ talvez devido ao número reduzido de sementes do lote, além do fato do trabalho ter sido feito de forma manual. Scleronema micranthum foi a essência de menor percentagem de pureza. No teste de corte somente Stryphnodendron guiantnse apresentou um número alto de embriốes danificados $(66,0 \%)$ enquanto que nas outras espécies este número foi bem reduzido.

Quanto ao periodo de germinação e sua distribuição, as espécies foram classificadas em três grupos. O primeiro, de sementes que requerem um periodo relativa. n nte curto para ter suas sementes germinadas (Fig. 1) com um máximo de trinta dias (C. micrantha, $C$. longipendula, A. spruceanum e $H$. courbaril). O segundo, representado na Fig. 2. seria de espécies que tiveram suas sementes germinadas num máximo de 60 dias (E. williamii, C. villosum, $D$. odorata $\in D$. excelsa) e, por último, as que ultrapassaram 60 dias (Fig. 3), de periodo mais longo (S. guianense, P. pendula, S. micranthum e C. guianensis). Nos gráficos (Fig. 1, 2 e 3), podemos visualizar bem a grande diferenciação entre as espécies quanto ao poder e período germinativo de suas sementes, além de sua distribuição por este período. O início do período de germinação foi distinto para todas as espécies estudadas, variando de dois (Anacardium spruceanum) a trinta dias (Dipteryx odorata). Também a duração deste período foi bem diversa. Enquanto Cariniana micrantha teve todas suas sementes germinadas em vinte e cinco dias, espécies como Styrphnodendron guianense tiveram germinação por um período de tempo muito maior. Também a distribuiçăo diária do número de sementes germinadas foi bastante diferenciada entre as espécies. Apenas as espécies de período curto apresentaram dias de alta percentagem de germinação durante o período, sendo que todas as outras espécies tiveram uma distribuição bastante uniforme de germinação durante os noventa dias observados. Nas curvas de percentagem do total de sementes germinadas por dia, podemos verificar que Hymenaea courbaril, por exemplo, no décimo primeiro dia apresentou vinte por cento de germinação, caindo para quatro por cento quatro dias depois, ao passo que $S$. micranthum apresenta uma distribuição bastante uniforme com apenas um leve aumento no quadragéssimo quinto dia.

Foi realizado um teste não-paramétrico $U$ de Mann-Whitney, para a distribuição diária de sementes germinadas nas quatro amostras e para cada espécie, cujos resultados revelaram que houve diferenças significativas ao nivel de $5 \%$ para as locações das amostras toma- 

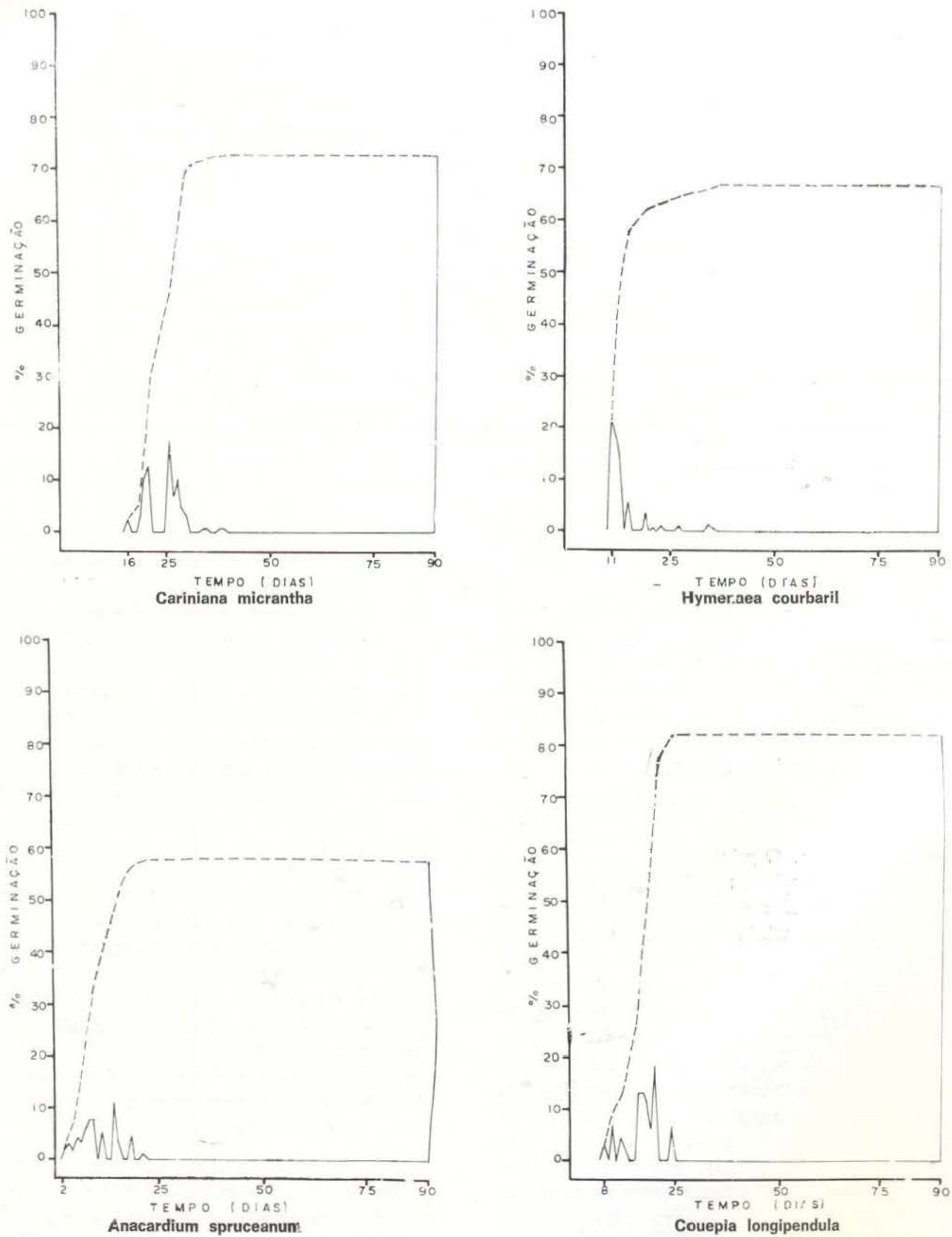

Fig. 1 - Curvas de espécies com período curto de gerıninação. .... Total germinaao por dia, acumulado \% Total germinado por dia \% 

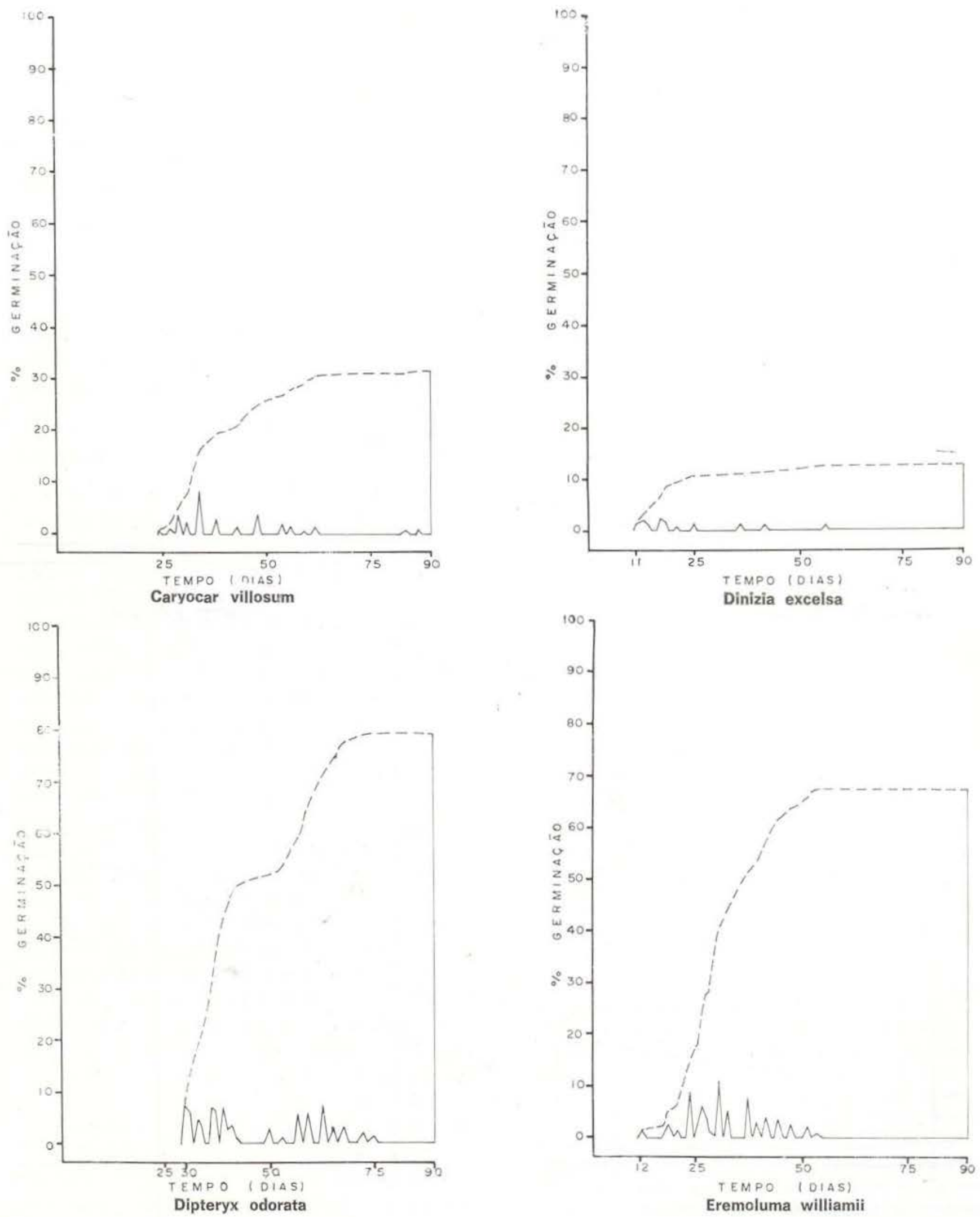

Fig. 2 - Curvas de espécies de períodos germinativos médios, .... Total germinado por dia, acumulado \% Total germinado por dia \% 

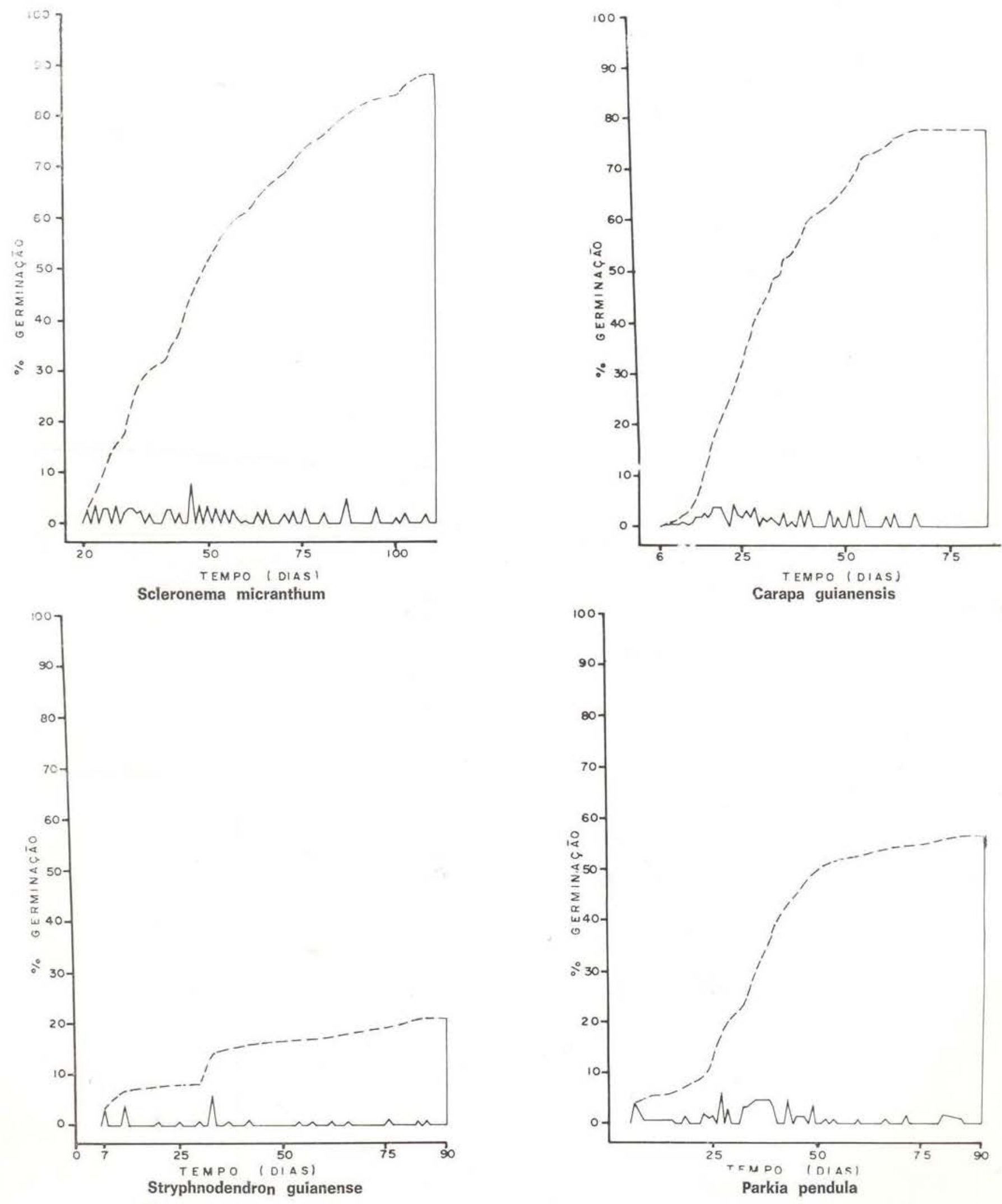

Fig. 3 - Curvas de espécies com períodos de germinação longos. .... Total germinado por dia, acumulado \% Total germinado por dia \% 
das entre si, duas a duas. Também o número total de sementes que germinaram em cada uma das quatro amostras (Quadro 3) foi variável. Foi feito também um teste de correlação entre as porcentagens de germinação e o peso de 1000 sementes puras em grama (Quadro 2), através da expressāo:

$r_{s}=1-\frac{6 \sum_{i=1}^{n} d_{i}^{2}}{n\left(n^{2}-\right.} \quad$ (coeticiente de

correlação de Spearman). O valor calculado de $r_{\mathrm{s}}=0,589$ foi significativo ao nivel de $5 \%$, demonstrando uma tencência de sementes com maior peso apresentarem maiores porcentagens de germinação.

\section{DIScUssão}

Progressivamente, vamos tendo maior co. nhecimento sobre nossas essências florestais, partindo para experimentaçōes técnicas quanto às suas culturas. Os resultados obtidos neste trabalho dão conta de um campo que deve ser melhor pesquisado a fim de se obter a técnica mais econômica de produção de mudas para cada espécie. Nossos resultados mostraram que qualquer projeto futuro deve levar em consideração as particularidades de cada espécie. Sementes de baixa percentagem de germinação ou de períodos longos de germinação deverão sofrer tratamertos pré-germinativos adequados. O período mais crítico das operações do viveire é o que germinam as sementes e os dias subsequientes, pois chuvas fortes e outras más condiçōes como doenças, podem causar danos e prejuízos. A obtençăo de uma maior uniformidade na germinação de espécies de valor econômico, além de facilitar os trabalhos do viveirista vão eliminar perdas e aumentar o rendimento na produção de mudas destas essências. Anacardium spruceanum, Cariniana micrantha, Hymenaea courbaril e Couepia Iongipendula mostraram ser eficientes tanto na percentagem total de germinação quanto no período que levaram para germinar. Dipteryx odorata, Parkia pendula, Scleronema micrathum e Carapa guianensis, apesar de apresentarem percentagem germinativa superior a $50 \%$, tiveram periodos germinativos longos, sendo importante um estudo de tratamento que uniformize este processo. Apenas três espécies apresentaram problemas de baixa germinação e longos períodos: Dinizia excelsa, Stryphnodendron guianense e Caryocar villosum. Também com estas espécies devem ser testados métodos que aumentem esta percentagem e diminuam o período germinativo. A correlação encontrada entre o peso de 1000 sementes $\mathrm{e}$ as respectivas porcentagens de germinação, mostrou que sementes com maior peso têm uma percentagem de germinaçăo maior, indicando que o teor de reserva destas semen. tes tem importância na germinação. Convém ainda dizer, que é possivel, aumentar as percentagens de germinação, sem custo extra com tratamentos, por meio de seleção genética.

QUADRO 3 - Número de sementes que ger minaram em cada amostra de 50 sementes

\begin{tabular}{|c|c|c|c|c|c|}
\hline \multirow{2}{*}{ ESPECIES } & \multicolumn{4}{|c|}{ AMOSTRAS } & \multirow{2}{*}{$\begin{array}{c}\text { No To- } \\
\text { tal de } \\
\text { Semen- } \\
\text { tes }\end{array}$} \\
\hline & $1 .{ }^{n}$ & 2.a & $3 .^{a}$ & 4." & \\
\hline Dinizia excelsa & 8 & 6 & 8 & 5 & 27 \\
\hline Cariniana micrantha & 33 & 33 & 36 & 45 & 147 \\
\hline Stryphnodendron guianense & 11 & 12 & 5 & 25 & 53 \\
\hline Couepia Iongipendula & 43 & 37 & 42 & 45 & 167 \\
\hline Carapa guianensis & 39 & 42 & 39 & 36 & 156 \\
\hline Scleronema micranthum & 42 & 46 & 41 & 47 & 176 \\
\hline Eremoluma williamii & 42 & 33 & 28 & 32 & 135 \\
\hline Caryocar villosum & 16 & 20 & 8 & 20 & 64 \\
\hline Parkia pendula & 32 & 25 & 29 & 31 & 117 \\
\hline Dipteryx odorata & 31 & 45 & 47 & 34 & 157 \\
\hline Anacardium spruceanum & 24 & 15 & 46 & 30 & 115 \\
\hline Hymenaea courbaril & 34 & 34 & 31 & 35 & 134 \\
\hline
\end{tabular}

\section{SUMMARY}

The germination of twelve forest species from the Manaus region were investigated with the object of obtaining information for the cultivating of these species. Germination percentage curves in function of time were made showing the distinction between species with regard to the cultural value of these seeds as well as the germination percentage and period. Additional tests were realized (purity, cut, fluctuation and weight) giving a better characterization to the lots studied. The authors point out a good germinative potencial for these species, being that nine of them present a higher than fifty germination percentage without any type of treatment during a maximum period of ninety days after sowing. 


\section{BIBLIOGRAFIA}

Araujo, V.C.

1967 - Sobre a germinação de Aniba (Lauraceae) 1 - Aniba duckei Kostermanns (Pau-rosaitauba). INPA, Bot., 23. 14 p. il.

1970 - Sobre a germinaçăo de Aniba (Lauraceae) Aniba canelilla (H.B.K.) Mez Casca preciosa - INPA, Bot. Manaus, 12, $9 \mathrm{p}$.

1971 - Sobre a germinação do mogno (Aguano) Swietenia macrophylla King. Acta Amazonica, Manaus, $1(3): 59-69$.

DeICHMANN, V. von

1967 - Noções sobre sementes e viveiro florestais. Curitiba-Paraná. 196 p. il.

Glesinger, E.

1960 - Practicas de plantación forestal en America Latina, $F A O-1 . \circ \mathrm{Ed}$. $499 \mathrm{p}$. il.
PANDOLFO, C,

1978 - A floresta amazônica brasileira - Enfoque econômico - Ecológico - SUDAM. Belém.

Peretra, A.P. \& Pedroso, L.M.

1973 - Influência da produndidade de semeadura em algumas essências florestais na Amazônia. In: Anais do II Congresso Fiorestal Brasileiro, : 54-56. Curitiba Paraná.

PRODEPEF (Projeto de Desenvolvimento e Pesquisa Florestal)

1976 - Centro de Pesquisas Florestais de Amazônia. Programação Técnica. Série Divulgações, n.o 9.

(Aceito para publicação em 25/04/79) 